\title{
Genome-wide SNP data unravel the ancestry and signatures of divergent selection in
}

3 Arnav Mehrotra ${ }^{1}$, Bharat Bhushan ${ }^{1}$, Karthikeyan $A^{1}$, Akansha Singh ${ }^{1}$, Snehasmita Panda ${ }^{1}$, Meenu

$4 \quad$ Bhati $^{2}$, Manjit Panigrahi ${ }^{1}$, Triveni Dutt ${ }^{1}$, Bishnu P. Mishra $^{1}$, Hubert Pausch $^{2}$, Amit Kumar $^{1}$

5

11 Corresponding author : Amit Kumar: Division of Animal Genetics, ICAR - Indian Veterinary

12 Research Institute, Izatnangar, Bareilly - 243122, UP, India (Corresponding author Email:

13 vetamitchandan07@gmail.com; ORCID ID: http://orcid.org/0000-0002-4423-7881) 


\section{Summary}

29 The evolution and domestication of pigs is a complex and ongoing process. Despite its rich

30 biodiversity and proximity to the geographical origins of Sus scrofa domesticus, the place of Indian

31 pigs in the global phylogeny is unclear. Using microarray-derived (porcine 60K SNP chip)

32 genotypes of 11 Ghurrah pigs from North-Western India and a public dataset comprising 2113 pigs

33 of 146 breeds, we determined the genomic ancestry of Ghurrah pigs and compared their genetic

34 constitution to European and Asian breeds to ascertain signatures of divergent selection. Results

35 showed that Ghurrah pigs contain genes of Asian and European ancestry with signs of inter-species

36 introgression. Using Admixture LD - decay statistics, the European admixture event was dated to

37 the recent past, coinciding with the start of cross-breeding efforts in India. The complex Asian

38 ancestry pattern of the breed resembled that of wild boars of South - Central China and Thailand,

39 possibly suggesting introgression from an Indian wild boar relative. $F_{\mathrm{ST}}$ and XP - EHH

40 comparisons with Asian breeds highlighted divergent selection in genomic regions associated with

41 odontogenesis and skeletal muscle development. Comparisons with European commercial breeds

42 revealed that genomic regions governing olfaction and response to sensory stimulation were under

43 selection in Ghurrah pigs. QTL for meat and carcass traits also showed divergent selection between

44 European breeds and Ghurrah pigs. Our results present the first genomic characterization of an

45 Indian pig breed using dense microarray-derived genotypes and highlight the importance of further

46 genomic characterization of Indian domestic and wild pigs.

48 Keywords; Admixture; Introgression; Phylogeny; Tropical; Sus Scrofa 


\section{Introduction}

54 Within the last decade, the implementation of high throughput SNP genotyping and whole-genome

55 sequencing has provided an in-depth insight into the demographic history of the domestic pig.

56 The origins of the Sus scrofa species have been traced to the Mainland South East Asia (MSEA) and

57 Island South East Asia (ISEA), about 5 million years ago (Mya) (Frantz et al., 2013). Subsequently,

58 pigs dispersed all over Eurasia and the divergence between the European and Asian wild boars has

59 been dated back to around $1 \mathrm{Mya}$, with independent domestication events taking place in the two

60 continents about 10,000 years ago (Groenen 2016). The geographical differences, diverse

61 domestication practices and more recently, commercial breeding have resulted in remarkable

62 morphological and physiological differences between pig breeds. Studies carried out in European

63 and Chinese pig breeds have identified selective sweeps in the genomic regions related to teeth,

64 bone and nervous system development (Frantz et al., 2015) $\square$, olfactory and immune response

65 pathways (Paudel et al., 2015) $\square$ and feed intake and fat deposition (Wilkinson et al., 2013).

67 Geographically and ecologically, India occupies a unique position in the world with its four

68 biodiversity hotspots, and proximity to South-East Asia which has been the origin of the pig and

69 home to several other extant Sus species (Dobney et al., 2008; Myers et al., 2000) $\square$. India also

70 possesses three sub-species of the S. scrofa (cristatus, davidi and affinis) (Meijaard et al., 2011). So

71 far, the only studies attempting to place the Indian pig breeds in a global phylogenetic context have

72 been based on mitochondrial DNA (Singh et al., 2016) $\square$. However, mtDNA based studies are less

73 suited to resolve the phylogeny due to a limited number of loci involved (Frantz et al., 2013) $\square$.

74 In this study we characterize the Indian Ghurrah pig breed using a genome wide panel of markers.

75 Ghurrah is a lightly built breed with adult weight about $48 \mathrm{~kg}$. The black coated Ghurrah pigs are

76 native to the Rohilkhand region of North - Western India (Ghurrah Pig, NBAGR breed profiles). 
77 We explore the ancestry of Ghurrah pigs, assess admixture patterns with global breeds and attempt

78 to place the breed in a global phylogenetic tree using a public dataset consisting of 146 pig breeds.

79 Moreover, we compare it to a subset of Asian and European breeds using $F_{\mathrm{ST}}$ and $\mathrm{XP}$ - EHH to

80 discover regions of diversifying selection.

\section{Materials and Methods}

\section{Samples and data}

85 Blood samples were collected from the jugular vein of 11 Ghurrah pigs kept at the AICRP farm at

86 IVRI, Izatnagar in Bareilly according to regulations of the Institute Animal Ethics Committee

87 (IAEC). The pigs were procured from the surrounding regions of Bareilly $\left(28.3670^{\circ} \mathrm{N}, 79.4304^{\circ}\right.$

88 E). Genomic DNA was extracted using standard protocols and genotyped on the Illumina

89 PorcineSNP60 BeadChip comprising 62,163 SNPs.

90 To place the Ghurrah breed in a global phylogenetic context, we also retrieved the data that were

91 gathered by Yang et al., (2017) containing the genotypes of 2113 pigs belonging to 146 domestic,

92 wild and commercial breeds. This dataset also contained genotypes of 39 animals from 5 Sus

93 species other than Sus scrofa. Detailed information about the breeds is provided in Supplementary

94 file 1 of Yang et al., (2017).

95 SNP coordinates based on the newer Sscrofa11.1 genome assembly were assigned to the dataset

96 using the UCSC liftOver function. Using PLINK 1.9 (Chang et al., 2015) $\square$, we removed SNPs

97 which were unmapped, on sex chromosomes, had a minor allele frequency less than 0.05 (--maf

980.05 ) and a call rate below 90\% (--geno 0.1). 11 individuals with more than $10 \%$ missing genotypes

99 (--mind 0.1) were also removed, leaving a combined dataset of 2113 individuals and 45,323 SNPs,

100 including Ghurrah $(\mathrm{n}=2113)$. 


\section{Principal component analysis and population admixture}

105 We pruned the data for SNPs in linkage disequilibrium using the PLINK v1.9 command -indep106 pairwise 505 0.2, leaving 10,211 independent SNPs. The genomic relationship matrix among the 107 samples was built and the too 20 principal components were extracted using GCTA 1.93 (Yang et al., 108 2011).

109 To infer the global ancestry of the Ghurrah pig, we ran an anaylsis using the ADMIXTURE V1.3

110 SOFTWARE (Alexander \& Lange 2011). Initially, the analysis was run with all 147 breeds, followed

111 by a subset of 24 breeds belonging to the different breed clusters outlined by Yang et al., (2017).

112 This subset included South Chinese domestic breeds (CNDH, CNLU, CNWZ), East and Central

113 Chinese domestic breeds (CNMS, CNEH, CNJH), Asian wild boars (CNWB1, CNWB2, CNWB3,

114 CNWB4, THWB, RUWB1, RUWB2), European commercial breeds (PIT1, LDR1, LWT1),

115 European wild boars (NEWB,ITWB1), other Sus species (BABA, SBSB, SCEL, SVSV, PHAF) and

116 Ghurrah (GHUR). Abbreviations and sample sizes of the 24 breeds considered are listed in Table

117 S1.

118 ADMIXTURE was run for $\mathrm{K}$ values ranging from $2-24$ with cross validation. Each run was repeated

1195 times with a random seed to gain accurate estimates (Liu et al., 2020). The results were

120 visualized using PoNG (Behr et al., 2016).

\section{TREEMIX analysis}

123 To complement the AdMIXTURE analysis we used TREemix 1.13 (PicKRell \& PRITCHARD 2012) to

124 analyze the 24 breed subset. This approach draws a maximum likelihood phylogram which

125 facilitates to depict ancestral divergence and admixture between the breeds. We ran TREEMIX fitting

126 up to 10 migration pathways, choosing the African Warthog (PHAF) as the root of the tree. 


\section{Timing of admixture}

130 We ran ALDER 1.03 (Loh et al., 2013) $\square \square$ to estimate the time since the admixture event occurred.

131 In brief, ALDER estimates the rate of LD decay as a result of the admixture between the populations

132 through a weighted LD statistic. There are two additional advantages to using this approach. First, it

133 is robust against the effect of SNP array ascertainment bias, and second, it can detect the false

134 positive admixture signals arising due to non-admixture LD caused by events such as population

135 bottlenecks. For this analysis, we set Ghurrah as the admixed population, and all the European and

136 Chinese breeds as surrogates for the admixing populations. The program initially computed a one-

137 reference curve for each breed to determine signals of admixture - i.e. whether a lineage

138 represented by that breed was involved in admixture of Ghurrah, then it used the breeds detected to

139 be involved in admixture, in a two-reference test to estimate the timing of admixture.

\section{Signatures of divergent selection}

142 The Indian Ghurrah pigs were compared with the three major European commercial breeds -

143 Landrace (LDR1), Large White Yorkshire (LWT1) and Pietran (PIT1), and three Asian domestic

144 breeds - Guangdongdahuabai (CNDH), Diannanxiaoer (CNDN) and Luchuan (CNLU). These three

145 Asian breeds were chosen as they belonged to the south-central Chinese population which had the

146 least introgression from European breeds (Yang et al., 2017). Two different approaches were

147 employed to assess signatures of selection, i.e., $F_{\mathrm{ST}}$ (Weir \& Cockerham 1984) and Cross

148 Population Extended Haplotype Homozygosity (XP-EHH) (Sabeti et al., 2007). The pairwise $F_{\text {ST }}$

149 calculations were carried out using VCFTOOLS (Danecek et al., 2011), with a sliding window of 500

$150 \mathrm{~Kb}$ and a $250 \mathrm{~Kb}$ step size. The $F_{\mathrm{ST}}$ values were assigned $Z$-scores in the R package SCALE to

151 facilitate selection for significant regions. Separately, for both the breed groups (Asian and

152 European), the average Z-score for each $500 \mathrm{~kb}$ region was calculated. Regions with an average Z-

153 score four standard deviations above the mean $(Z \geq 4)$, were retained for further analysis. For 
154 calculation of XP-EHH, haplotypes were inferred using BEAGLE v5.1 (Browning et al., 2018) and

155 analyzed through the R-package REHH (Gautier et al., 2017) to calculate the $p_{\text {XP-EHH }}$ statistic

156 between Ghurrah and each of the six breeds under comparison. Average $p_{\mathrm{XP}-\mathrm{EHH}}$ values were derived

157 for each SNP within both the breed groups. To avoid false positives, we scanned the genome in 500

$158 \mathrm{~Kb}$ windows with $250 \mathrm{~Kb}$ overlap and retained the regions with at least two markers with a $p_{\mathrm{XP}-\mathrm{EHH}}$

159 value greater than the $99.97^{\text {th }}$ percentile as suggested by Gautier et al., (2017) and Sabeti et al.,

160 (2007). Genes within the regions identified by the $F_{\mathrm{ST}}$ and XP-EHH statistic were obtained from

161 Ensembl Biomart (Cunningham et al., 2019). Functional profiling of the selected genes was done

162 using g:PrOFILER (Raudvere et al., 2019). Enrichment of GO terms and pathways was determined at

163 a FDR adjusted $p$-value of 0.05 .

\section{Results and Discussion}

166 Principal component analysis and population admixture

167 To place the Ghurrah breed in a global context, we performed a PCA on a dataset containing samples from

168 Ghurrah and 146 other breeds. Each breed was marked as a single point on the plot by averaging the

169 eigenvectors of all individuals within a breed for each principal component. The top principal components

170 (PC) revealed three distinct clusters containing Asian, European and other Suid species. PC1 separated the

171 Asian from European breeds while PC2 separated the wild from domestic breeds (Fig. 1a). Ghurrah was

172 placed in the middle of the two clusters along with CNST, CSLM, CNLC and RUMS. All these Asian breeds

173 have been reported to contain significant (> 20\%) European admixture (Yang et al., 2017), suggesting that

174 the ancestral pattern is similar for Ghurrah. PC3 separated the S. scrofa animals from the other Suid species,

175 with Ghurrah being one of the prominent outliers of the S. scrofa cluster (Fig. 1b).

177 To further explore the findings presented by PCA, we ran ADMIXTURE. An initial analysis that considered all

178147 breeds outlined the complex ancestry of the Ghurrah pig. To facilitate the interpretation of the ancestry,

179 we then ran the analysis on a subset of 24 breeds belonging to different wild and domestic breed clusters (see

180 Methods). The lowest cross-validation error was obtained for K = 19 (Fig. S1). The barplots of the 19 
181 admixture runs can be found in supplementary Fig. S2. K = 3 divided the populations in distinct clusters

182 belonging to Asian and European pigs, and other suid species (Fig 2). Ghurrah pigs had 45.5\% Asian, 33.8\%

183 European and $20.6 \%$ inheritance from the other suid species. Ghurrah had the highest level of interspecies

184 introgression, followed by the Thai and Chinese Wild boars (7-9\%). K = 4 divided the Asian ancestry into

185 distinct Southern and Eastern Chinese clusters with Ghurrah showing a pre-dominant South Chinese ancestry

$186(36.4 \%)$. At higher level of $\mathrm{K}=8$, the increasingly complex ancestry of the Ghurrah pig resembled that of

187 the South Chinese and Thai wild boars, which coalesced into a distinct ancestral block at K = 11 and Ghurrah

188 shared more than $59.4 \%$ of its ancestral proportion with the aforementioned Asian wild boars with the rest

189 coming from European ( 28\%) and other suid species (12\%). Ghurrah was separated into its own cluster at

$190 \quad K=14$.

\section{TREEMIX analysis}

193 The admixture results were further supported by the phylogram constructed by TREEMIX (Fig. 3a and 3b).

194 The northern (RUWB1, RUWB2, CNWB2) and southern (CNWB1, CNWB3, CNWB4) wild boars of Asia

195 were assigned different branches in the Asian clade, as were the southern and central-eastern Chinese

196 domestic breeds. The European clade had similar distinct branches for the wild and commercial breeds.

197 Ghurrah was not placed within these two clades, but instead was a sister group to the Chinese and European

198 breeds. This tree explained $98.8 \%$ of the covariance observed between populations.

199 A complex history of admixture of Sus scrofa was suggested when migration edges were added to the graph.

200 The addition of 10 migration paths explained $99.8 \%$ of the observed covariance between populations and

201 allowed us to recapitulate the phylogenetic tree created by Frantz et al., (2013) who used sequence data to

202 correctly group different suid species. Admixture between Ghurrah and European commercial breeds as well

203 as South Chinese breeds was represented by two migration edges. The admixture among the Chinese and

204 European breeds over the last two centuries, which has been well documented in the literature (Groenen

205 2016), has also been captured in our phylogram. However, the effect of ascertainment bias of the SNP chip

206 markers is also visible in the relatively shorter branch lengths of Asian pigs compared to their European

207 counterparts in Fig 3b. 


\section{Timing of admixture}

211 In the pairwise testing involving all European and Asian breeds using ALDER, we got 118 significant

212 combinations (Table S2). A number of European wild boars were the surrogates for the European lineage,

213 and several Eastern and Central Chinese domestic breeds and Asian wild boars represented the Asian lineage.

214 The strongest signal $(\mathrm{z}=15.33, \mathrm{p}=1.3 \mathrm{e}-49)$ was obtained when the Iberian Wild Boar (IBWB) and Chinese

215 Jinhua pig $(\mathrm{CNJH})$ were taken as surrogates for the two lineages, respectively. The estimated time of

216 admixture by ALDER's weighted LD statistic was $13.52 \pm 0.88$ generations. Taking the average generation

217 interval of a pig as 1.5 years, this equates to the admixture event taking place approximately 20 years ago.

218 Similar time frames were drawn from the pairwise comparisons of different surrogate breeds, although with

219 varying standard errors. The relatively recent admixture detected in our study corresponds with the initiation

220 of cross-breeding efforts in India in the late eighties and nineties through the introduction of European

221 germplasm, with Large White and Landrace being the predominant exotic breeds (Rajkhowa et al., 2018) $\square$.

222 Even though we could reconcile the European inheritance found in our analysis with the records of cross-

223 breeding in the region, we can only hypothesize about the origin of the complex Asian inheritance of

224 Ghurrah pig. Our admixture results show the resemblance between the genomic ancestry patterns of Ghurrah

225 and the Asian wild boars (Fig. 2 and Fig. S2). This pattern of the ancestry in Ghurrah may have been derived

226 from a wild relative such as the Indian wild boar or Sus scrofa cristatus which is indigenous to North -

227 Western India (Meijaard et al., 2011). Due to the migratory and backyard rearing system under which

228 Ghurrah is kept, an introgression of genes from wild boars may happen frequently. Such mobile domestic

229 herding systems have been shown to be responsible for gene flow between domestic and wild boars

230 elsewhere (Frantz et al., 2011). The wild boar inheritance could also explain the fraction of ancestry from

231 other ISEA suid species in Ghurrah, as we could detect similar signals of interspecies introgression in the

232 admixture blocks of other Asian wild boars. However, any definitive conclusion would require genotype data

233 for the other Indian pig breeds including Sus scrofa cristatus. 


\section{Signatures of divergent selection between Ghurrah and Chinese pigs}

238 In the pairwise comparisons between Ghurrah and three Chinese breeds (CNDN, CNDH, CNLU), we found

23911 regions $(5 \mathrm{Mb})$ through $F_{\mathrm{ST}}$ and 2 regions $(2 \mathrm{Mb})$ through XP-EHH analyses (Fig. $4 \mathrm{a}$ and $4 \mathrm{~b}$ ), which met

240 their respective significance thresholds of $Z \geq 4$ and $p_{\text {XP-EHH }} \geq 2.09$. There was no overlap between the

241 significantly identified regions by the two methods. The detected genomic regions contained 69 genes (Table

242 S3). Through these genes, six significantly enriched (FDR adj. P < 0.05) GO:BP terms were identified by

243 g:Profiler, all of which related to Odontogenesis (Table S4).

244 The $F_{\text {ST }}$ analysis pointed towards a $750 \mathrm{~Kb}$ region on SSC8 $(67.25-68 \mathrm{Mb})$ which contained the most

245 significantly differentiated markers $(\mathrm{Z} \geq 5.11)$. This region contains the $A M T N, A M B N$ and $E N A M$ genes,

246 which code for the amelotin, ameloblastin and enamelin proteins, respectively, involved in the formation and

247 maturation of tooth enamel (Gasse et al., 2015). Genes involved in biomineralization of dental tissue have

248 been reported as candidates for diversifying selection in several mammals including pigs, humans and

249 canines (Machado et al., 2016). Dental morphometry in pigs show a systematic variation with changing

250 geographical location and domestication status, with distinct phenotypes found across the breeds (Evin et al.,

251 2015), and our findings in the Indian pig further supports this notion.

252 Another divergently selected region includes a gene poor segment on SSC15 (98.5-99.25) which is in the

253 vicinity of the $M S T N$ gene $(94.62 \mathrm{Mb})$ that is associated with skeletal muscle growth. We also identified

254 other regions flanking this gene which showed significant differentiation $(\mathrm{Z} \geq 3)$ between the breeds, but fell

255 below our set threshold. Divergent selection between the Asian domestic and wild boars has been attributed

256 to this region previously (Zhu et al., 2017). XP-EHH analysis revealed a region on SSC15 (25 - $26 \mathrm{Mb})$

257 which overlapped QTLs for lean meat and fat percentage (Rothammer et al., 2014).

\section{Signatures of divergent selection between Ghurrah and commercial European pigs}

260 Comparisons with the three European breeds (LWT, LDR, PIT), 14 significant $(\mathrm{Z} \geq 4)$ regions amounting to

261 a combined non-overlapping length of $6 \mathrm{Mb}$ were identified by $F_{\mathrm{ST}}$ (Fig. 4C; Table S5). Several regions

262 around the MSTN gene (SSC15: 89 - $99 \mathrm{Mb}$ ) were also detected in this comparison. A search on the

263 PigQTLdb (https://www.animalgenome.org/QTLdb/pig/) showed this region overlapping with QTLs for 
264 meat and carcass traits namely, backfat percentage, muscle protein percentage and meat tenderness, all of

265 which under strong artificial selection in commercial breeds.

266 The strongest $F_{\mathrm{ST}}$ signal for divergence was observed in a $5.25 \mathrm{Mb}$ region on SSC8 $(45.75-51 \mathrm{Mb})$. This

267 region contains GLRB, GRIA2 and GSX2 genes, the human orthologs of which are involved in synaptic

268 transmission and nervous system development (Lueken et al., 2017; Salpietro et al., 2019). Further evidence

269 of neurological and behavioral divergence between the breed groups was found by the results of the XP-EHH

270 analysis ( $p_{\text {XP-EHH }} \geq 2.40$, Fig. 4 d). Two regions of $3 \mathrm{Mb}$ cumulative length on SSC2 (14-15 Mb, 16-18 Mb)

271 containing a cluster of genes coding for olfactory receptors were detected to be under selection in the

272 Ghurrah pigs. The indigenous pigs of India are reared in a free - range scavenging system (Rahman et al.,

273 2020) and depend on their olfactory abilities to find feedstuff and mating partners, which may be a reason for

274 these genes to be under selection in the Ghurrah breed compared to the commercial breeds which are reared

275 and fed in captivity. These results were underlined by the functional profiling of the 103 genes present in the

27616 regions detected by $F_{\mathrm{ST}}$ and XP-EHH analysis, where $23 \mathrm{GO}$ :BP terms were found significantly enriched

277 (Table S6). The GO terms pertaining to response to sensory stimuli and olfaction had the lowest FDR

278 adjusted $p$-values $\left(\mathrm{p}_{\text {adj }}<10^{-6}\right)$. KEGG and REACTOME pathways related to olfactory signaling and G

279 protein-coupled receptor transduction were also significantly $\left(\mathrm{p}_{\mathrm{adj}}<10^{-2}\right)$ enriched.

281 To conclude, many of the extant pig breeds in the world show a complex inheritance drawing from European

282 and Asian lineages, and the Indian Ghurrah pig is no exception. However, it is unique with respect to the

283 relatively high proportion of inter-species introgression and a pattern of inheritance resembling those of the

284 Asian wild boars. In this study, we had the constraints of a limited sample size and the ascertainment bias

285 arising from the design of the Porcine60K SNP array. Also, the rather low resolution of the porcine SNP

286 array is a limitation to comprehensively identify genomic regions responsible for divergence within and

287 between the breeds. However, our results provide a first genomic characterization of the Ghurrah breed and

288 revealed putative targets of selection. We took into account the constraints of the current dataset by

289 employing complementary approaches to arrive at our results. Yet, validating our findings using whole

290 genome sequence data from a larger set of animals is required. Our study also suggests that genomic 
291 characterization of other Indian pig breeds, especially the Indian wild boar, is important to develop a

292 thorough understanding of the evolution and domestication of Sus scrofa.

293

\section{Acknowledgments}

295 The authors thank Director, IVRI and the staff at the AICRP farm at IVRI. The work was supported by the

296 CAAST - ACLH project of NAHEP, funded by the ICAR and the World Bank.

\section{Data availability}

299 The public dataset used in the analysis is available from the Dryad Repository at

300 http://dx.doi.org/10.5061/dryad.30tk6. The data for Ghurrah pigs is available at

\section{$301 \quad 10.6084 / \mathrm{m} 9$. figshare.12204671}

302

\section{Conflict of interest}

304 The authors declare that there are no competing financial interests. 


\section{References}

Alexander D.H., Lange K., 2011. Enhancements to the ADMIXTURE algorithm for individual ancestry estimation. BMC bioinformatics 12, 246.

Behr A.A., Liu K.Z., Liu-Fang G., Nakka P., Ramachandran S., 2016. pong: Fast analysis and visualization of latent clusters in population genetic data. Bioinformatics 32, 2817-2823.

Browning B.L., Zhou Y., Browning S.R., 2018. A one-penny imputed genome from next-generation reference panels. The American Journal of Human Genetics 103, 338-348.

Chang C.C., Chow C.C., Tellier L.C.A.M., Vattikuti S., Purcell S.M., Lee J.J., 2015. Second-generation PLINK: rising to the challenge of larger and richer datasets. Gigascience 4, s13742-015.

Cunningham F., Achuthan P., Akanni W., Allen J., Amode M.R., Armean I.M., Bennett R., Bhai J., Billis K., Boddu S., 2019. Ensembl 2019. Nucleic acids research 47, D745-D751.

Danecek P., Auton A., Abecasis G., Albers C.A., Banks E., DePristo M.A., Handsaker R.E., Lunter G., Marth G.T., Sherry S.T., 2011. The variant call format and VCFtools. Bioinformatics 27, 2156-2158.

Dobney K., Cucchi T., Larson G., 2008. The pigs of Island Southeast Asia and the Pacific: New evidence for taxonomic status and human-mediated dispersal. Asian Perspectives 47, 59-74.

Evin A., Dobney K., Schafberg R., Owen J., Strand Vidarsdottir U., Larson G., Cucchi T., 2015. Phenotype and animal domestication: A study of dental variation between domestic, wild, captive, hybrid and insular Sus scrofa. BMC Evolutionary Biology 15. 
343 Frantz L.A.F., Schraiber J.G., Madsen O., Megens H.J., Bosse M., Paudel Y., Semiadi G., Meijaard E., Li N.,

344 Crooijmans R.P.M.A., Archibald A.L., Slatkin M., Schook L.B., Larson G., Groenen M.A.M., 2013.

345 Genome sequencing reveals fine scale diversification and reticulation history during speciation in Sus.

$346 \quad$ Genome Biology 14, 1-12.

347 Frantz L.A.F., Schraiber J.G., Madsen O., Megens H.J., Cagan A., Bosse M., Paudel Y., Crooijmans

348 R.P.M.A., Larson G., Groenen M.A.M., 2015. Evidence of long-term gene flow and selection during

349 domestication from analyses of Eurasian wild and domestic pig genomes. Nature Genetics 47, 1141-

$350 \quad 1148$

351 Gasse B., Chiari Y., Silvent J., Davit-Béal T., Sire J.Y., 2015. Amelotin: An enamel matrix protein that

352 experienced distinct evolutionary histories in amphibians, sauropsids and mammals Evolutionary

353 developmental biology and morphology. BMC Evolutionary Biology 15, 1-16.

354 Gautier M., Klassmann A., Vitalis R., 2017. rehh 2.0: a reimplementation of the R package rehh to detect

355 positive selection from haplotype structure. Molecular Ecology Resources 17, 78-90.

356 Ghurrah pig, 2020. ICAR- National Bureau of Animal Genetic Resources, viewed 18 April 2020,

$357 \quad$ http://14.139.252.116/ghurrah.html

358 Groenen M.A.M., 2016. A decade of pig genome sequencing: A window on pig domestication and evolution.

359 Genetics Selection Evolution 48, 23.

360

Liu C.-C., Shringarpure S., Lange K., Novembre J., 2020. Exploring Population Structure with Admixture Models and Principal Component Analysis, in: Dutheil, J.Y., (Ed.), Statistical Population Genomics.

Loh P.R., Lipson M., Patterson N., Moorjani P., Pickrell J.K., Reich D., Berger B., 2013. Inferring admixture

364 histories of human populations using linkage disequilibrium. Genetics 193, 1233-1254.

365 Lueken U., Kuhn M., Yang Y., Straube B., Kircher T., Wittchen H.U., Pfleiderer B., Arolt V., Wittmann A., 366 Ströhle A., 2017. Modulation of defensive reactivity by GLRB allelic variation: converging evidence 367 from an intermediate phenotype approach. Translational psychiatry 7, 1227. 
368 Machado J.P., Philip S., Maldonado E., ÖBrien S.J., Johnson W.E., Antunes A., 2016. Positive selection

369 linked with generation of novel mammalian dentition patterns. Genome Biology and Evolution 8, $370 \quad 2748-2759$.

371 Meijaard E., d'Huart J., Oliver W.L.R., 2011. Family Suidae, (Pigs). In: Handbook of the Mammals of the $372 \quad$ World 2, pp. 248-291.

373 Myers N., Mittermeler R.A., Mittermeler C.G., Da Fonseca G.A.B., Kent J., 2000. Biodiversity hotspots for 374 conservation priorities. Nature 403, 853-858.

375 Paudel Y., Madsen O., Megens H.J., Frantz L.A.F., Bosse M., Crooijmans R.P.M.A., Groenen M.A.M., 2015. 376 Copy number variation in the speciation of pigs: A possible prominent role for olfactory receptors. 377 BMC Genomics 16, 1-14.

378 Pickrell J. Pritchard J., 2012. Inference of population splits and mixtures from genome-wide allele frequency 379 data. Nature Precedings, 1.

380 Rahman M., Phookan A., Zaman G.U.Z., Ahmed S.I., Deori S., Hoque E., 2020. Performance of Doom pigs 381 under different production systems in subtropical ecosystem of north east India. Indian Journal of $382 \quad$ Animal Sciences 90, 292-295.

383 Rajkhowa S., Banik S., Mohan N.H., Barman K., Das P.J., Kumar Sunil, Kumar Satish, 2018. Annual Report 384 of AICRP on Pig 2018-2019.

385 Raudvere U., Kolberg L., Kuzmin I., Arak T., Adler P., Peterson H., Vilo J., 2019. g: Profiler: a web server 386 for functional enrichment analysis and conversions of gene lists, (2019 update). Nucleic acids research $387 \quad 47$, W191-W198.

388 Rothammer S., Kremer P. V, Bernau M., Fernandez-Figares I., Pfister-Schär J., Medugorac I., Scholz A.M., 389 2014. Genome-wide QTL mapping of nine body composition and bone mineral density traits in pigs. $390 \quad$ Genetics Selection Evolution 46, 68. 
Sabeti P.C., Varilly P., Fry B., Lohmueller J., Hostetter E., Cotsapas C., Xie X., Byrne E.H., McCarroll S.A., populations. Nature 449, 913-918.

Salpietro V., Dixon C.L., Guo H., Bello O.D., Vandrovcova J., Efthymiou S., Maroofian R., Heimer G., Burglen L., Valence S., 2019. AMPA receptor GluA2 subunit defects are a cause of neurodevelopmental disorders. Nature communications 10, 1-16.

Singh A.P., Jadav K.K., Kumar D., Rajput N., Srivastav A.B., Sarkhel B.C., 2016. Complete mitochondrial genome sequencing of central Indian domestic pig. Mitochondrial DNA Part B 1, 949-950.

Weir B.S. Cockerham C.C., 1984. Estimating F statistics for the analysis of population structure. evolution $38,1358-1370$.

Yang B., Cui L., Perez-Enciso M., Traspov A., Crooijmans R.P.M.A., Zinovieva N., Schook L.B., Archibald

Wilkinson S., Lu Z.H., Megens H.J., Archibald A.L., Haley C., Jackson I.J., Groenen M.A.M., Crooijmans R.P.M.A., Ogden R., Wiener P., 2013. Signatures of Diversifying Selection in European Pig Breeds. PLoS Genetics 9. A., Gatphayak K., Knorr C., Triantafyllidis A., Alexandri P., Semiadi G., Hanotte O., Dias D., Dovč P., Uimari P., Iacolina L., Scandura M., Groenen M.A.M., Huang L., Megens H.J., 2017. Genome-wide SNP data unveils the globalization of domesticated pigs. Genetics Selection Evolution 49, 71.

[dataset] Yang B., Cui L., Perez-Enciso M., Traspov A., Crooijmans R.P.M.A., Zinovieva N., Schook L.B., Archibald A., Gatphayak K., Knorr C., Triantafyllidis A., Alexandri P., Semiadi G., Hanotte O., Dias

415 Zhu Y., Li W., Yang B., Zhang Z., Ai H., Ren J., Huang L., 2017. Signatures of selection and interspecies 
416 introgression in the genome of Chinese domestic pigs. Genome Biology and Evolution 9, 2592-2603.

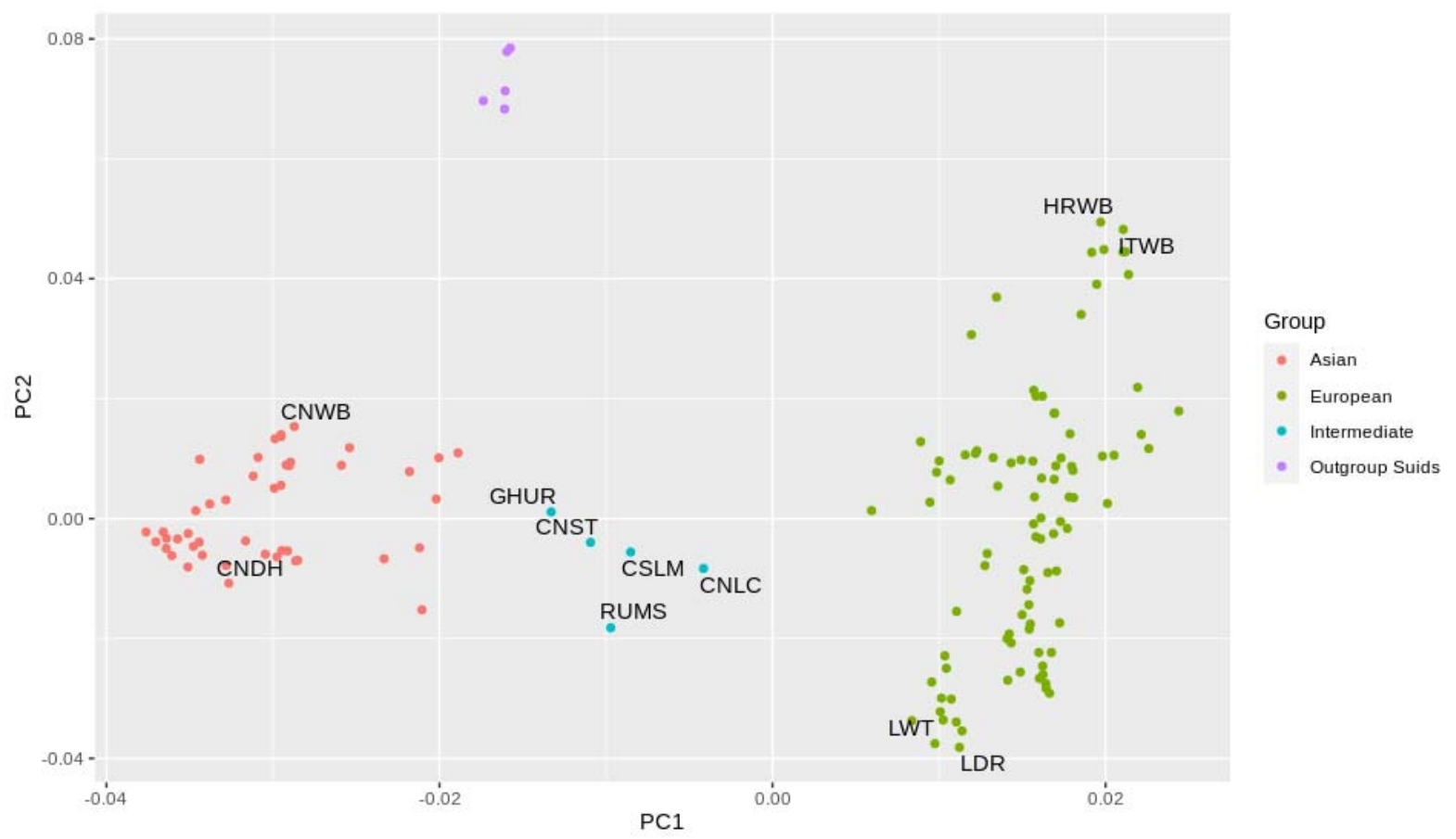

429 Figure 1a. Separation of the 147 pig breeds along the first and second principal components.

430 CNWB, Chinese Wild Boar; CNDH, Guangdongdahuabai; GHUR, Ghurrah; CNST, Sutai; RUMS, Russian Minisibs;

431 CSLM, Large White x Meishan; CNLC, Lichahei; LWT, Large White Yorkshire; LDR, Landrace; HRWB, Croatian

432 Wild Boar; ITWB, Italian Wild Boar. 
bioRxiv preprint doi: https://doi.org/10.1101/2020.09.24.312009; this version posted September 24, 2020. The copyright holder for this preprint (which was not certified by peer review) is the author/funder, who has granted bioRxiv a license to display the preprint in perpetuity. It is made available under aCC-BY-NC-ND 4.0 International license.

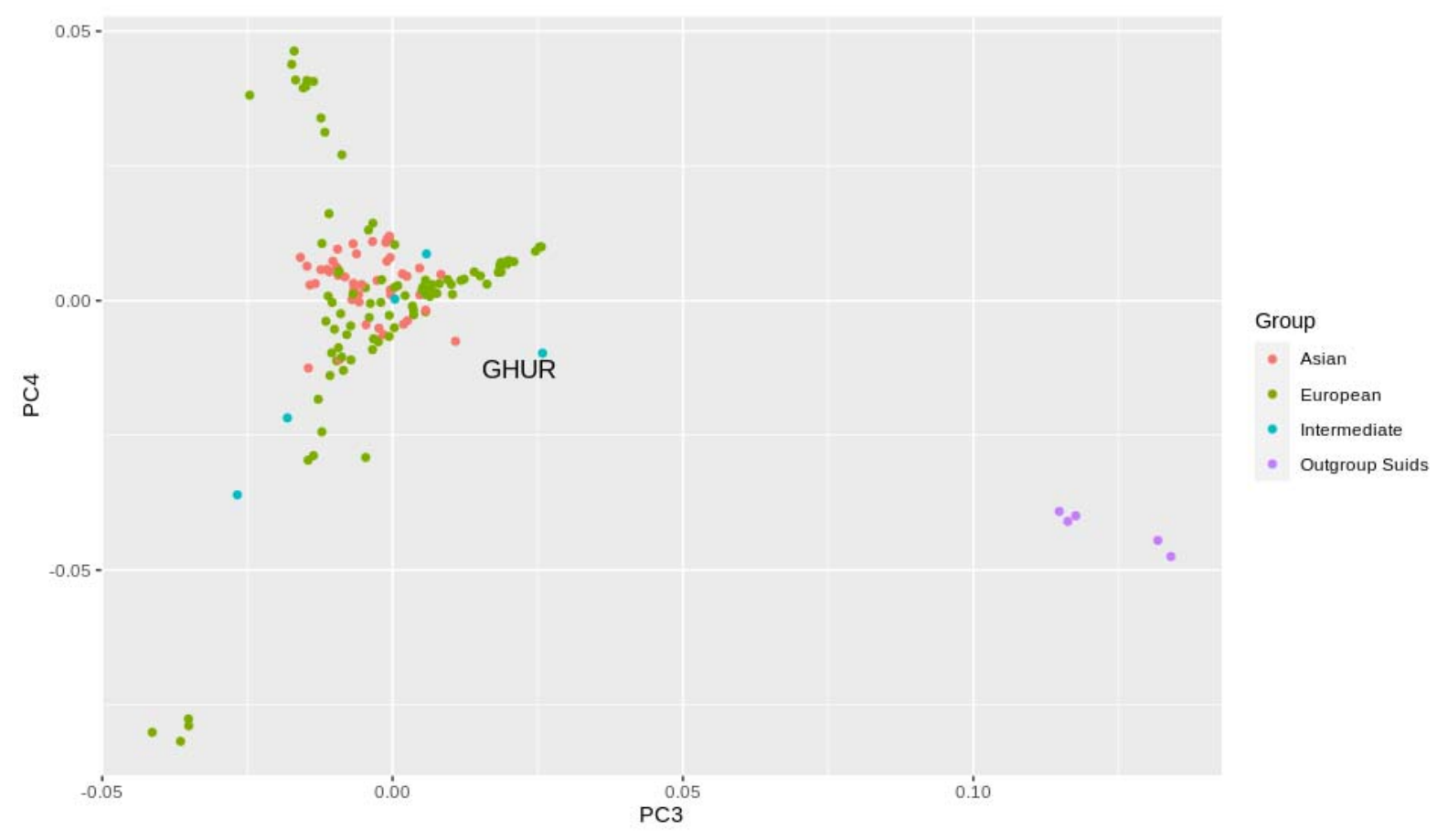

433

434 Figure 1b. Principal component analysis of all 147 pig breeds (PC3 and PC4 shown)

435

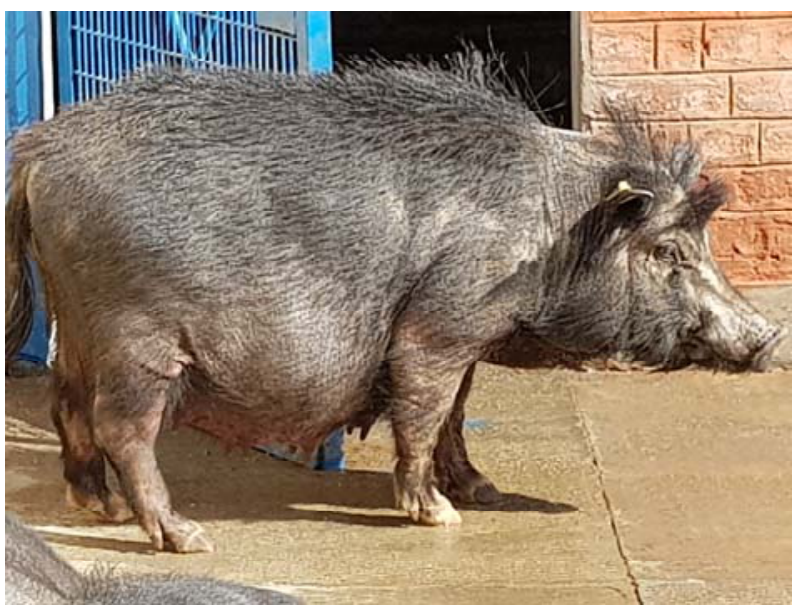

443

445 Figure 1c. A Ghurrah sow at IVRI, Izatnagar 
bioRxiv preprint doi: https://doi.org/10.1101/2020.09.24.312009; this version posted September 24, 2020. The copyright holder for this preprint (which was not certified by peer review) is the author/funder, who has granted bioRxiv a license to display the preprint in perpetuity. It is made available under aCC-BY-NC-ND 4.0 International license.

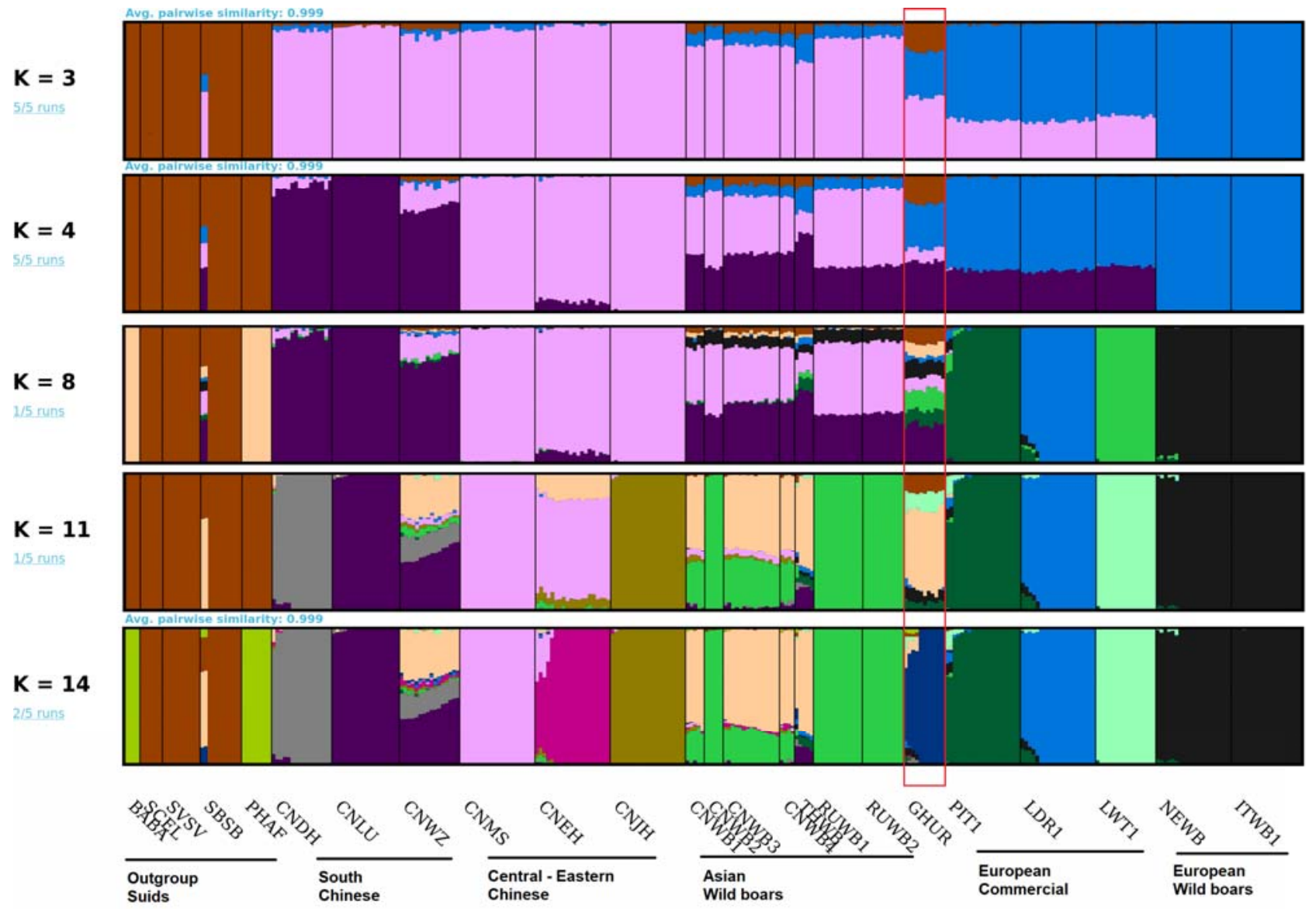

446 Fig 2. Admixture barplots with selected values of $\mathrm{K}$. The fractions on the left describe the number of identical runs out

447 of five, as calculated by PONG. For all values of K, see supplementary Figure S2. Breed abbreviations are provided in

448 supplementary table S1. 
bioRxiv preprint doi: https://doi.org/10.1101/2020.09.24.312009; this version posted September 24, 2020. The copyright holder for this preprint (which was not certified by peer review) is the author/funder, who has granted bioRxiv a license to display the preprint in perpetuity. It is made available under aCC-BY-NC-ND 4.0 International license.

461

462

463

464

465

466

467

468

469

470

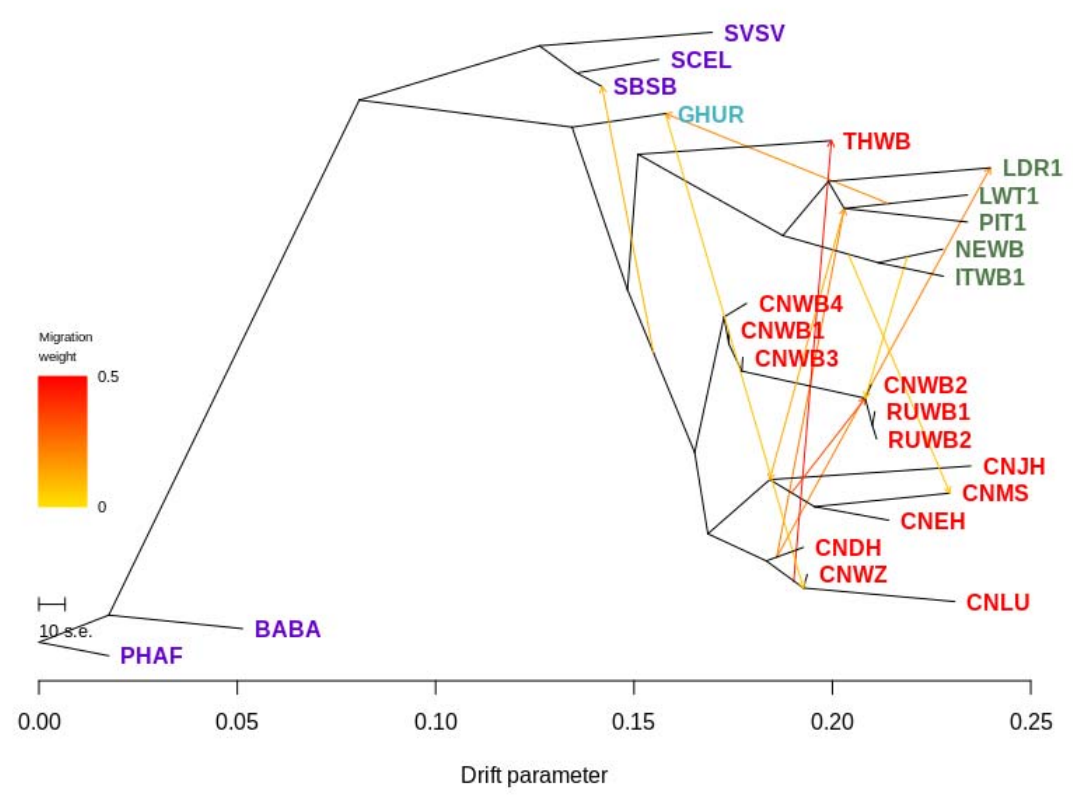

471

472 Fig 3a. Maximum likelihood phylogram with 10 migration edges. Admixture is shown among Chinese (Red)

473 and European breeds (Green), between Ghurrrah and European commercial breed and Ghurrah and South

474 Chinese breeds.

475

476 


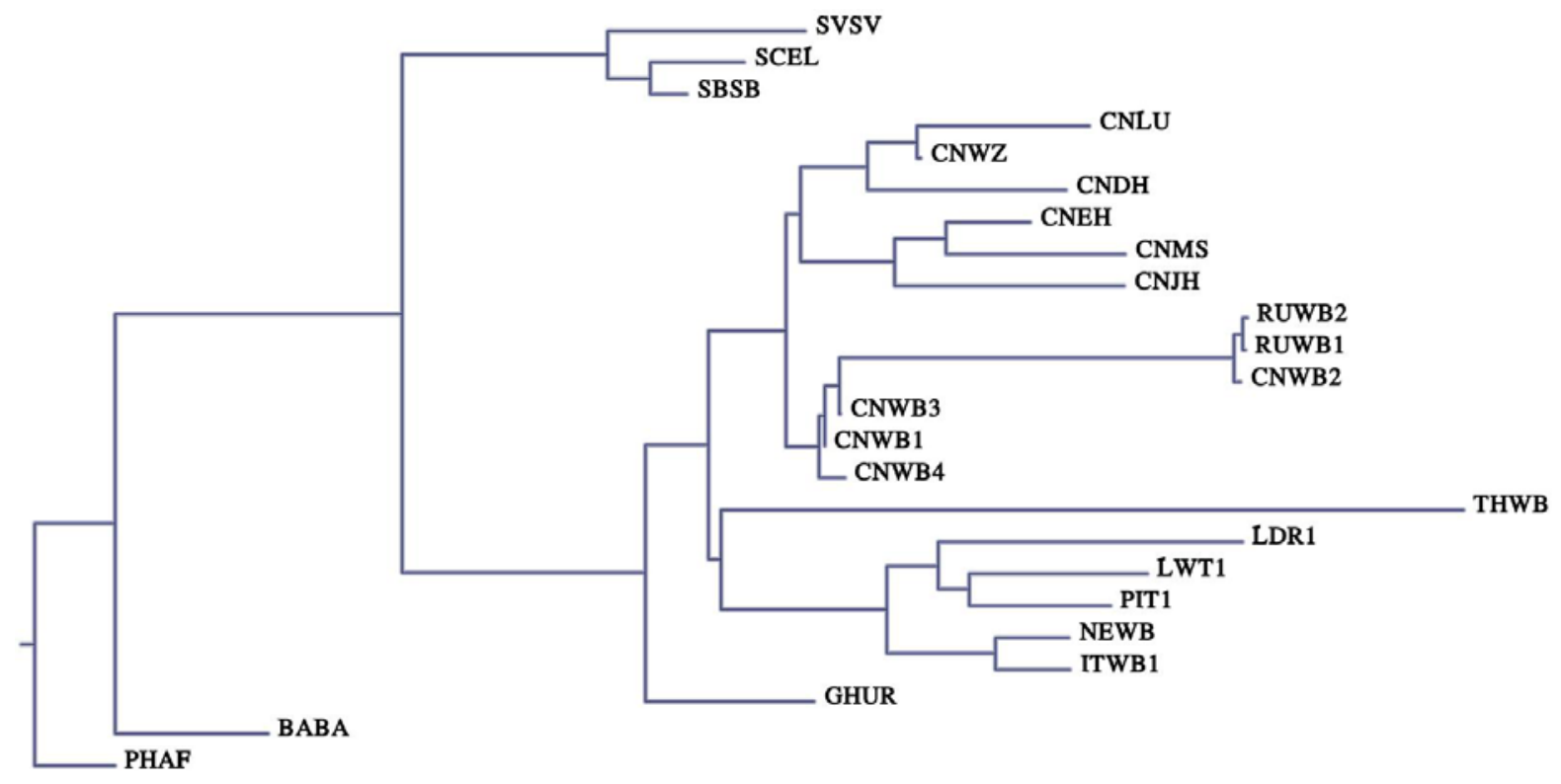

477 Fig 3b. The phylogram in Fig 3a presented as a conventional phylogenetic tree.

478

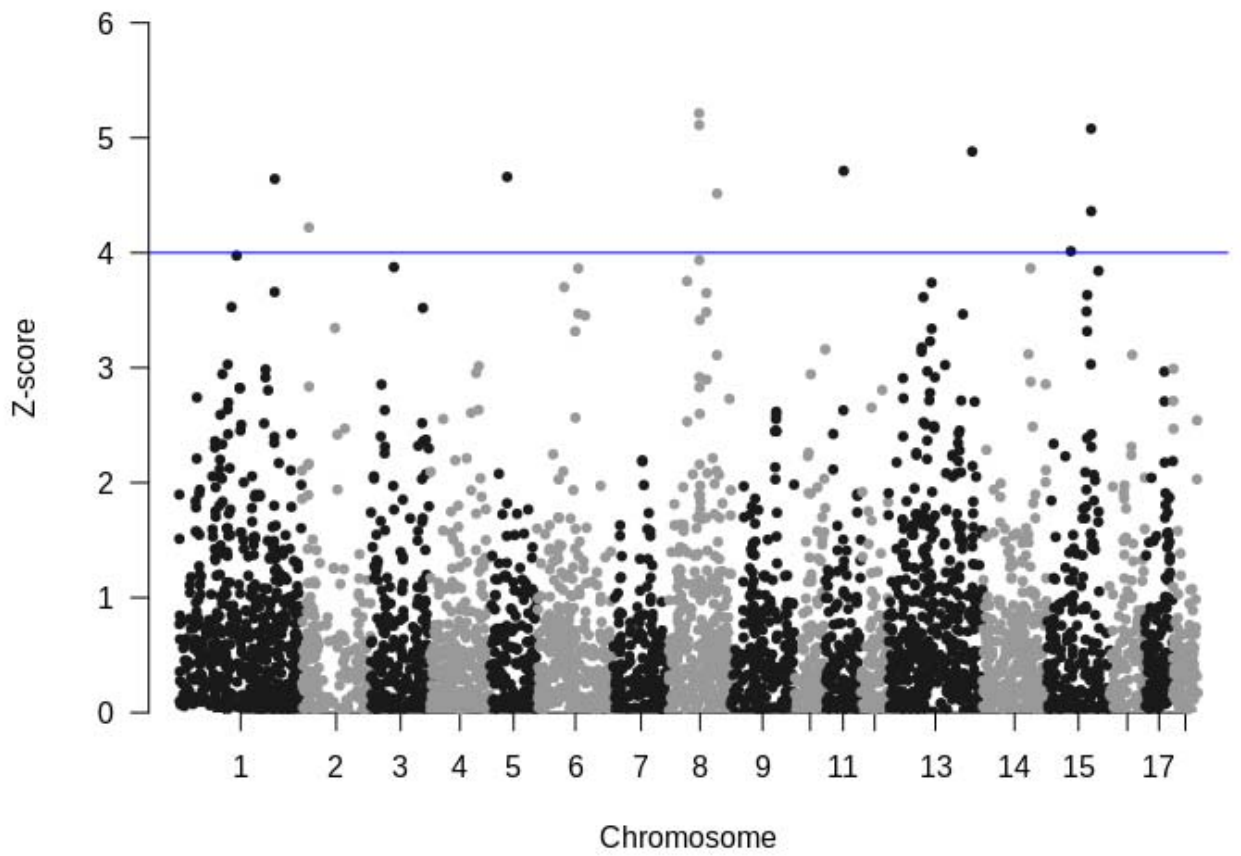

491 Figure 4a. - Manhattan plot of Z-transformed $F_{\mathrm{ST}}$ values for Ghurrah's comparison with 3 Chinese breeds.

492 Blue line indicates threshold of $Z \geq 4$. 
bioRxiv preprint doi: https://doi.org/10.1101/2020.09.24.312009; this version posted September 24, 2020. The copyright holder for this preprint (which was not certified by peer review) is the author/funder, who has granted bioRxiv a license to display the preprint in perpetuity. It is made available under aCC-BY-NC-ND 4.0 International license.

\section{Ghurrah vs Chinese breeds XPEHH}

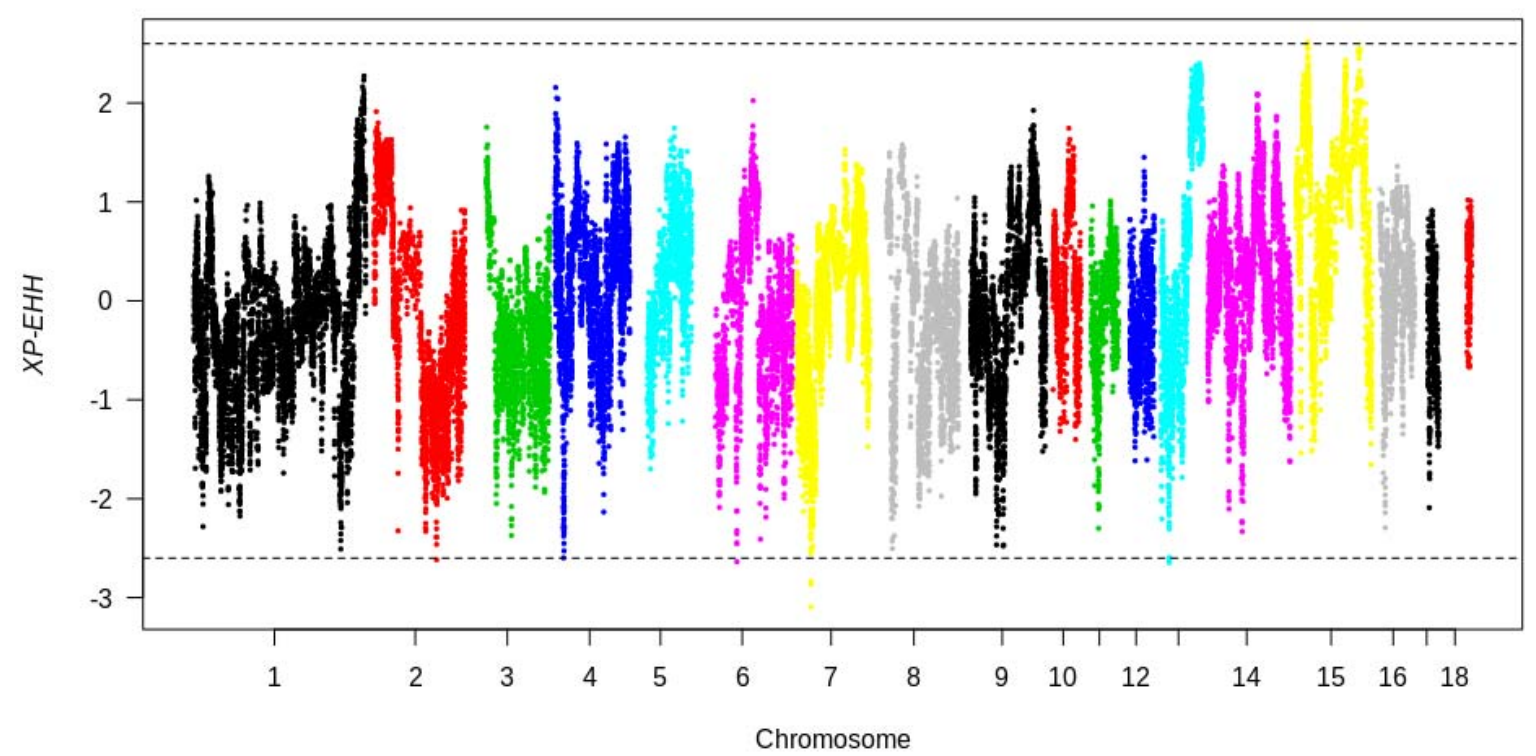

496 Figure 4b. - Plot of XP - EHH statistic for Ghurrah's comparison with 3 Chinese breeds. Positive value

497 indicates selection in Ghurrah; negative value indicates selection in Chinese pigs. Dotted lines indicate

498 threshold corresponding to $p_{\text {ХР-ЕHН }} \geq 2.09$.

\section{Ghurrah vs European breeds Fst (Z-transformed)}

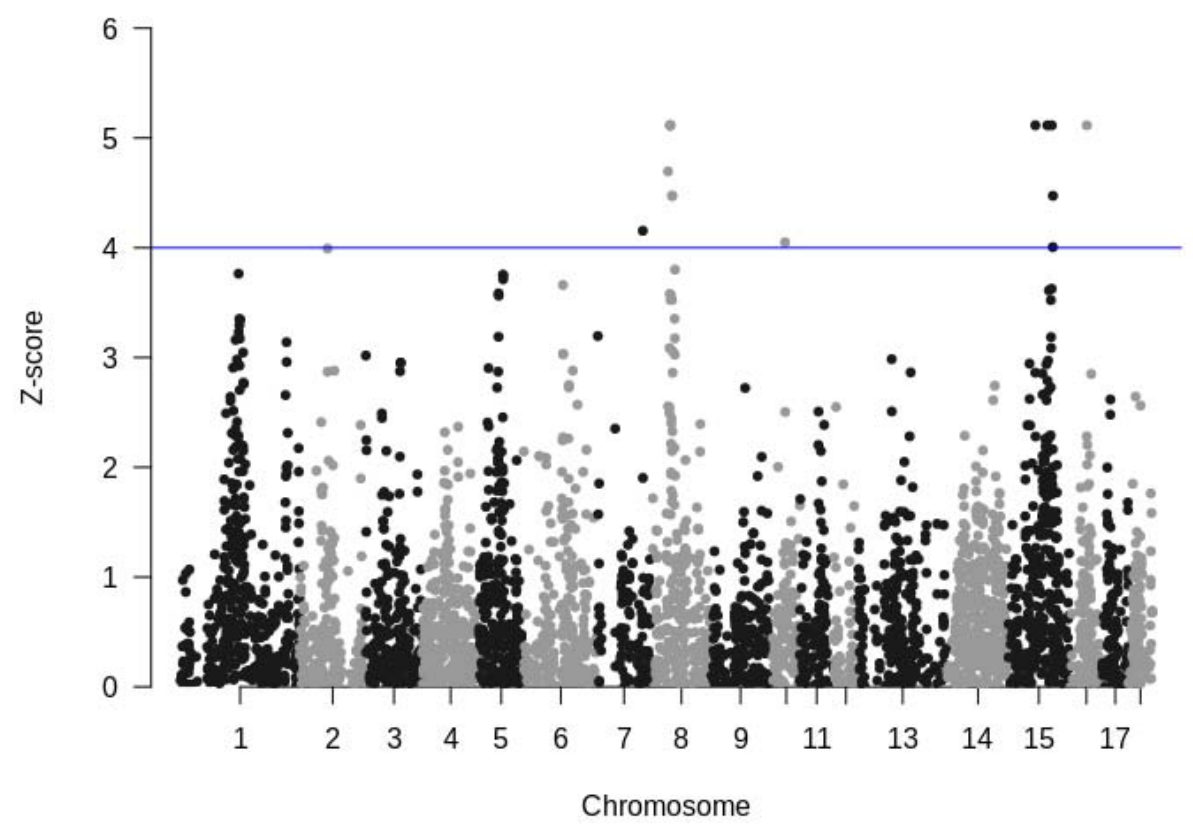


511 Figure 4c. - Manhattan plot of Z-transformed $F_{\mathrm{ST}}$ values for Ghurrah's comparison with 3 European breeds.

512 Blue line indicates threshold of $\mathrm{Z} \geq 4$.

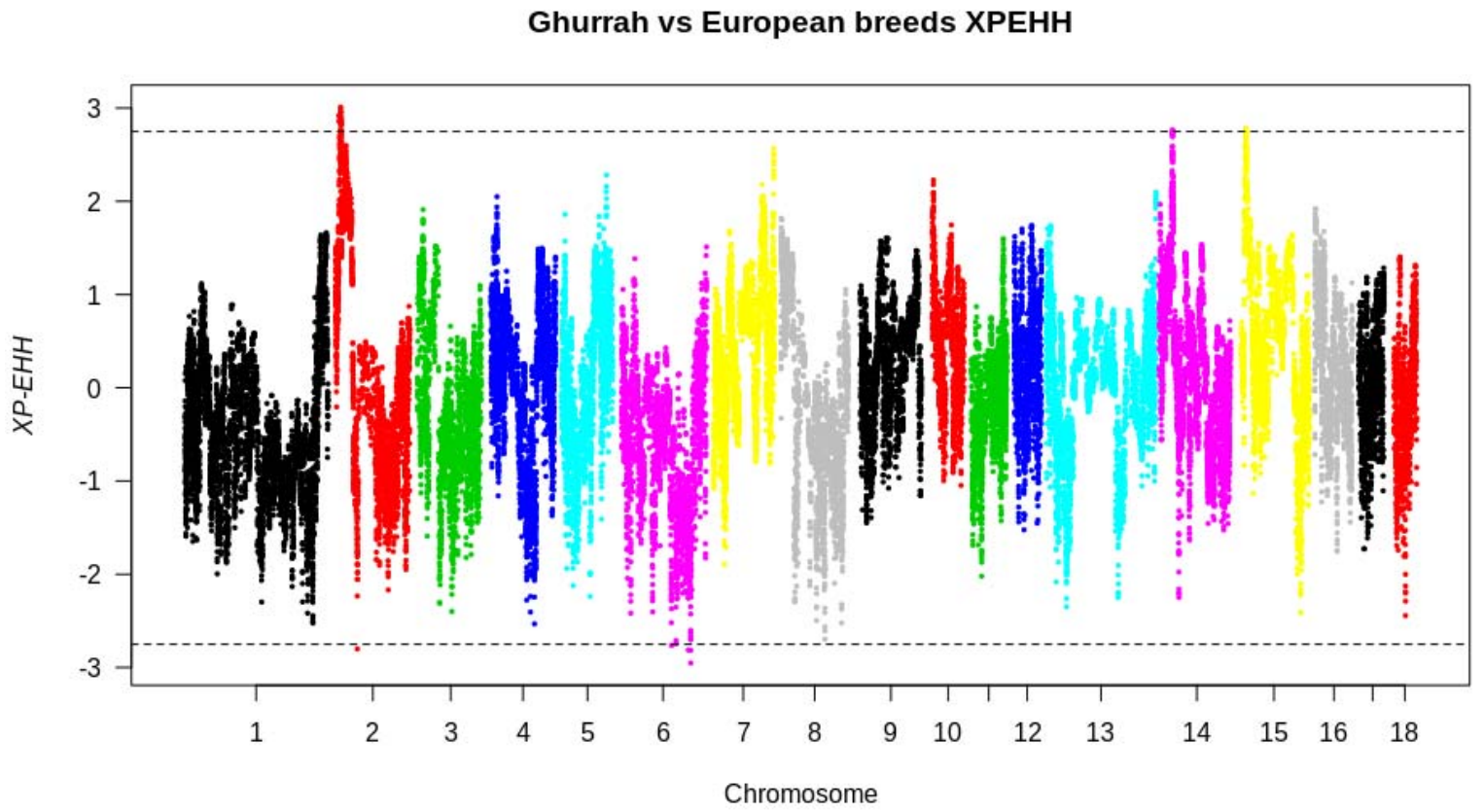

513 Figure 4d. - Plot of XP - EHH statistic for Ghurrah's comparison with 3 European breeds. Dotted lines

514 indicate threshold corresponding to $p_{\mathrm{XP}-\mathrm{EHH}} \geq 2.40$.

516 Supplement Legend

517 Table S1 - Abbreviation definitions and sample sizes of selected breeds included in the analysis.

518 Table S2 - Alder admixture results

519 Table S3 - List of regions and genes showing divergent selection between Ghurrah and Chinese pigs

520 Table S4 - List of significantly enriched GO terms for genes diverging between Ghurrah and Chinese pigs

521 Table S5 - List of regions and genes showing divergent selection between Ghurrah and European pigs

522 Table S6 - List of significantly enriched GO terms and pathways for genes diverging between Ghurrah and

523 European pigs

524 Figure S1 - Plot of ADMIXTURE cross validation errors with increasing K value

525 Figure $\mathrm{S} 2-$ Admixture plots of $\mathrm{K}=2$ to 19. 